\title{
Lifestyle Changes and Passive Smoking Risk in Rural Japan: Comparing Cross-Sectional Surveys
}

\author{
Tomoko Sumiyoshi ${ }^{1}$, Nao Seki ${ }^{1}$, Thimira Amarasinghe ${ }^{2}$, Sachini Kumari Thennakoon ${ }^{3} \&$ Sayaka Kubota $^{4}$ \\ ${ }^{1}$ School of Health Sciences, Niigata University, Niigata-shi, Niigata, Japan \\ ${ }^{2}$ Department of Nursing, Faculty of Allied Health Sciences, University of Peradeniya, Peradeniya, Sri Lanka \\ ${ }^{3}$ Faculty of Allied Health Sciences, University of Peradeniya, Sri Lanka \\ ${ }^{4}$ Department of Innovative Life Sciences, Niigata University of Pharmacy and Applied Life Sciences, Niigata-shi, \\ Niigata, Japan \\ Correspondence: Tomoko Sumiyoshi, School of Health Sciences, Niigata University, 2-746 Asahimachi-dori, \\ Chuo-ku, Niigata-shi, Niigata 951-8518, Japan. Tel: 81-25-227-0945. Fax: 81-25-227-0945.
}

Received: April 2, 2021 Accepted: May 6, 2021 Online Published: May 14, 2021

doi:10.5539/gjhs.v13n6p110

URL: https://doi.org/10.5539/gjhs.v13n6p110

\begin{abstract}
Recommended lifestyle and good mental/physical status in childhood are factors that facilitate lifelong health. This study investigated changes in the lifestyle of Japanese rural children over the past 15 years during which, tobacco-related education and lifestyle issues have significantly changed. This descriptive cross-sectional study was conducted in 2017 in Town A, rural, Japan. Data were collected using self-administered questionnaires, which were distributed to 360 students of two elementary schools and junior high schools in Town A. Daily activities, passive smoking exposure, mental/physical status, and Internet usage were evaluated and compared to data obtained from a similar survey conducted in 2002 in the same area and schools. Sleep time in 2017 was reduced compared to that in 2002 in both sexes but was significantly reduced only in girls. Exposure to passive smoking in 2017 was reduced compared to that in 2002, consistent with the significant reductions in the presence of family smokers (2002: 70.2\%; 2017: 46.9\%) and smoking in indoor living areas by family members $(2002: 45.7 \% ; 2017$ : $5.6 \%$ ). Furthermore, the rate of intended future smoking was significantly lower in 2017 than in 2002 for both boys and girls $(p<.001)$. Of 18 symptoms that can negatively affect students' physical and mental health status, 12 were significantly reduced in 2017 compared to those in 2002. The lifestyle of children in rural Japan has improved over the past 15 years and children maintain negative attitudes toward future smoking. However, more attention to technology-related lifestyle issues, including watching television and Internet usage, is warranted.
\end{abstract}

Keywords: child health, healthy lifestyle, mental health, cross-sectional study, smoking, technology

\section{Introduction}

The main modifiable risk factors for non-communicable diseases have been identified as smoking, unhealthy diet, sedentary lifestyle, and excessive alcohol consumption (World Health Organization, 2016). Numerous studies indicate that a proper lifestyle and good mental and physical status in childhood are important factors for promoting and maintaining lifelong health (Urakami et al., 2012) (Manning et al., 2016). Specifically, to reduce the risk of illness in adulthood and extend the healthy life expectancy, it is important to form and practice an appropriate lifestyle from childhood, and promote psychological development based on the growth process (Manning et al., 2016). Furthermore, it is very important to avoid studying the lifestyle of children only in the context of specific diseases, as the behavior of children can lead to the occurrence of various diseases, including non-communicable diseases, in early and later adulthood (Kotani et al., 1997).

Currently, Japan has an established basic policy aimed at extending the healthy life expectancy and realizing a vibrant society (Ministry of Health, Labour and Welfare, 2016). From the perspective of public health in Japan, studying the lifestyle and mental and physical status of children is critically important for local policy-making and reducing the prevalence of non-communicable diseases in future adult populations. In recent decades, the lifestyles of schoolchildren have undergone numerous changes because of urbanization and technological development (Tanaka et al., 2016), including changes in daily life activities, exercise patterns, media usage, and exposure to passive smoking. Most of these changes are not beneficial to the physical and mental health of students (Arakawa 
et al., 2001). Additionally, Japan is one of the largest tobacco-endemic countries in the world, and it is well known that smoking rates among adults are higher in rural and low-income areas than in urban areas. Furthermore, in Japan, families live in cramped quarters, and it is concerning that passive smoking poses a risk to the health of children (Fukuda et al., 2005). Therefore, student lifestyles and mental and physical health status must be surveyed as an initial step in the preventive process. However, most student health and lifestyle surveys are cross-sectional, and few studies have compared data from the same instrument over time.

The most recent survey of students in Town A was conducted 15 years ago (Tagami Town Health Management Center, 2003). However, over the last 15 years, Town A has undergone several socio-economic changes. The total land area of Town A is 3,171 ha, of which 921 ha $(29.0 \%)$ is farmland. While Town A is currently one of the leading rice-producing areas in Japan, the percentage of elderly people is increasing each year. The total population of Town A was 13,613 in 2002 and 11,383 in 2017, reflecting a decrease of approximately 2,000 people. The percentage of population younger than 14 years in Town A decreased from $15.4 \%$ in 2002 to $10.2 \%$ in 2017, while the percentage of the elderly population (aged over 65 years) increased from $19.9 \%$ in 2002 to $35.1 \%$ in 2017 . Accordingly, Town A symbolizes Japan's declining birthrate and aging population (Tagami town, Niigata statistics, 2020).

Based on the above considerations, the purpose of this study was to investigate changes in the lifestyles of children in Town A over the past 15 years, providing important baseline data for both policymakers and researchers.

\section{Method}

\subsection{Study Design}

This cross-sectional descriptive study was conducted in November 2017 at three schools, namely, two elementary and one junior high school, located in Town A, rural Japan. These three schools are the only schools in this town. Data were collected from students using self-administered questionnaires and analyzed in comparison with data from a similar study conducted in 2002 in Town A. The results of the 2002 survey have been distributed as statistical data by the local government (Tagami Town Health Management Center, 2003). The same questionnaire (Japanese version) used in 2002 and 2017 is shown in Appendix.

\subsection{Description of the Samples}

The sample of the 2017 survey comprised 360 students from two elementary schools ( $5^{\text {th }}$ and $6^{\text {th }}$ grades) and a junior high school ( $2^{\text {nd }}$ and $3^{\text {rd }}$ grades), with ages ranging from 10 to 15 years. The sample of the 2002 survey comprised 600 students from the same schools.

\subsection{Questionnaire}

The Japanese version of a self-administered questionnaire that assesses the lifestyle of children, standardized by the Health Ministry of Japan, was used as the study instrument. The questionnaire was edited in line with the objectives of this study and was validated by qualified personnel from the Board of Education of Town A. The questionnaire had three main categories: the student's daily lifestyle and perceptions; the student's current status and symptoms; and smoking-related concerns (family smoking habits and self-prediction on future smoking).

In the section on the student's daily lifestyle and perceptions, we obtained "yes/no" responses on a 2-point scale to the questions, "Do you consider yourself 'healthy'?" and "Do you do exercise outside of regular physical education classes?," as well as responses regarding the time spent sleeping and watching television. For the time spent watching television, students were asked to choose between "more than three hours per day" and "less than three hours per day," based on research showing that the average daily television viewing time in Japan is 168 min (Ministry of Internal Affairs and Communications, 2017).

The section on the student's current status and symptoms focused on the 7 symptoms used in the 2000 Japan Sport Council survey of students' dietary habits (Japan Sport Council, 2001). Responses were indicated on a 2-point "Yes/No" scale for 18 items about mental and physical symptoms, such as "feeling stressed" and "feeling tired often." Students could also provide reasons for their various responses.

In the section on smoking-related concerns, students indicated on a 2-point "Yes/No" scale whether a smoker lived with the family and whether the student intended to smoke in the future. Responses were also collected regarding where the smokers smoked and the student's opinions regarding the smokers in the family.

In addition, from the results of regular medical checkups conducted at the school, we obtained reliable measurements for height, weight, and obesity. The obesity level was calculated by the school nurse using the appropriate formula for each age. In accordance with the Ministry of Education, Culture, Sports, Science, and Technology (MEXT) school health statistics survey, an obesity index $\leqq-20 \%$ was classified as "thin," $-20 \%$ 
$<$ obesity index $<20 \%$ was classified as "standard," and $20 \% \leqq$ obesity index was classified as "obese" (Ministry of Education, Culture, Sports, Science and Technology in Japan, 2018).

\subsection{Statistical Analysis}

Excel 2017 spreadsheet software (Microsoft Japan Co., Ltd.) was used for the simple aggregation of data, and IBM SPSS Statistics 25.0 (SPSS, Inc., Chicago, IL, USA) was used for statistical analysis. The organized and categorized 2017 data were compared with data from the 2002 survey using Fisher's exact test and Student's t-test, as appropriate. The significance level was set at $p<.05$, with a confidence interval of $95 \%$.

\subsection{Ethical Considerations}

The process for obtaining informed consent included providing oral and written explanations to the students regarding the objectives of the study, consent process, and method to withdraw their participation. The students were further assured that their non-participation would not influence their academic achievement. The "Ethical Guidelines on Medical Research Targeting People" issued by the Ministry of Health, Labour, and Welfare were followed, and ethical approval for this study was obtained from the Medical Faculty Ethics Committee of the Niigata University (No. 2017-0199).

\section{Results}

In 2017, only 360 subjects were living in town A because the town's youth population had decreased dramatically owing to the aging society. Of the 360 students targeted in the 2017 survey, 303 (84.2\%) provided valid responses to the questionnaire. Among them, there were 137 boys (45.2\%) and 166 girls $(54.8 \%)$, and the average age was 12.8 years (range, 10-15 years). Of the 600 students targeted in the 2002 survey, 580 (96.7\%) provided valid responses (Table 1).

Table 1. Number of students in the 2002 and 2017 surveys according to grade

\begin{tabular}{|c|c|c|c|c|c|c|c|}
\hline & & \multicolumn{3}{|c|}{2002} & \multicolumn{3}{|c|}{2017} \\
\hline & & Boys & Girls & Total & Boys & Girls & Total \\
\hline & & $\mathrm{N}=293$ & $\mathrm{~N}=287$ & $\mathrm{~N}=580$ & $\mathrm{~N}=137$ & $\mathrm{~N}=166$ & $\mathrm{~N}=303$ \\
\hline \multirow[t]{2}{*}{ Elementary school } & 5th grade & 76 & 74 & 150 & 35 & 33 & 68 \\
\hline & 6 th grade & 71 & 60 & 131 & 29 & 40 & 69 \\
\hline \multirow[t]{2}{*}{ Junior high school } & 2nd grade & 76 & 69 & 145 & 34 & 44 & 78 \\
\hline & 3rd grade & 70 & 84 & 154 & 39 & 49 & 88 \\
\hline
\end{tabular}

\subsection{Students' Physiques}

Height and weight were generally greater in 2017 than in 2002 when stratified by both school and sex; the differences reached significance for height $(p=.034)$ and weight $(p=.005)$ in junior high school 2nd-grade girls. In contrast, obesity index levels (\%) did not significantly differ between 2002 and 2017 for both boys and girls (Tables 2 and 3). Boys in 2017 had lower obesity levels and were taller and slimmer than those in 2002, although the difference was not statistically significant. 
Table 2. Comparison of the body size of male students between the 2002 and 2017 surveys

\begin{tabular}{|c|c|c|c|c|c|}
\hline Boys & 2002 & & 2017 & & $p$ \\
\hline \multicolumn{6}{|l|}{ Elementary school } \\
\hline 5 th grade & $\mathrm{M}$ & SD & $\mathrm{M}$ & SD & \\
\hline Height (cm) & 139.7 & 6.3 & 140.0 & 6.5 & .854 \\
\hline Weight (kg) & 34.7 & 8.1 & 34.6 & 5.8 & .952 \\
\hline Obesity index (\%) & 1.8 & 16.1 & -0.8 & 15.7 & .444 \\
\hline \multicolumn{6}{|l|}{6 th grade } \\
\hline Height (cm) & 146.2 & 7.1 & 148.3 & 7.2 & .178 \\
\hline Weight (kg) & 39.4 & 9.0 & 39.9 & 9.0 & .790 \\
\hline Obesity index (\%) & 1.6 & 15.6 & -3.3 & 18.2 & .174 \\
\hline \multicolumn{6}{|l|}{ Junior high school } \\
\hline \multicolumn{6}{|l|}{ 2nd grade } \\
\hline Height $(\mathrm{cm})$ & 160.7 & 7.4 & 163.2 & 8.1 & .121 \\
\hline Weight (kg) & 48.1 & 9.1 & 51.4 & 11.5 & .110 \\
\hline Obesity index (\%) & -3.1 & 11.6 & -1.1 & 16.5 & .463 \\
\hline \multicolumn{6}{|l|}{ 3rd grade } \\
\hline Height $(\mathrm{cm})$ & 166.8 & 6.5 & 168.9 & 6.0 & .108 \\
\hline Weight (kg) & 55.4 & 9.9 & 56.0 & 9.3 & .774 \\
\hline Obesity index (\%) & 0.5 & 14.2 & -1.7 & 13.3 & .433 \\
\hline
\end{tabular}

Obesity index $=($ actual weight $(\mathrm{kg})-$ standard weight $(\mathrm{kg})) /$ standard weight $(\mathrm{kg})$ x 100 (\%). M: mean; SD: standard deviation.

Table 3. Comparison of the body size of female students between the 2002 and 2017 surveys

\begin{tabular}{|c|c|c|c|c|c|}
\hline Girls & 2002 & & 2017 & & $p$ \\
\hline \multicolumn{6}{|l|}{ Elementary school } \\
\hline 5 th grade & $\mathrm{M}$ & SD & $\mathrm{M}$ & SD & \\
\hline Height (cm) & 140.1 & 7.4 & 142.9 & 6.6 & .059 \\
\hline Weight (kg) & 34.4 & 8.0 & 36.5 & 7.4 & .196 \\
\hline Obesity index (\%) & 1.5 & 14.2 & 0.4 & 15.3 & .713 \\
\hline \multicolumn{6}{|l|}{6 th grade } \\
\hline Height $(\mathrm{cm})$ & 146.8 & 6.5 & 148.9 & 6.8 & .132 \\
\hline Weight (kg) & 39.1 & 8.8 & 39.8 & 8.4 & .734 \\
\hline Obesity index (\%) & 1.0 & 15.3 & -3.2 & 14.5 & .168 \\
\hline \multicolumn{6}{|l|}{ Junior high school } \\
\hline \multicolumn{6}{|l|}{ 2nd grade } \\
\hline Height $(\mathrm{cm})$ & 154.1 & 5.9 & 157.4 & 4.8 & $.005 * *$ \\
\hline Weight (kg) & 45.3 & 7.7 & 48.9 & 9.7 & $.038^{*}$ \\
\hline Obesity index (\%) & -2.5 & 12.7 & 0.2 & 18.1 & .369 \\
\hline \multicolumn{6}{|l|}{ 3rd grade } \\
\hline Height (cm) & 157.5 & 5.6 & 157.2 & 5.3 & .746 \\
\hline Weight (kg) & 50.7 & 8.5 & 50.6 & 6.2 & .964 \\
\hline Obesity index (\%) & 0.9 & 15.9 & 1.0 & 11.5 & .966 \\
\hline
\end{tabular}

$* p<.05, * * p<.001$; Obesity index $=($ actual weight $(\mathrm{kg})-$ standard weight $(\mathrm{kg})) /$ standard weight $(\mathrm{kg}) \mathrm{x} 100(\%)$. M: mean; SD: standard deviation. 


\subsection{Daily Lifestyle, Perceptions, Status, and Symptoms}

Table 4 shows the results of the comparisons in lifestyle, perceptions, and general complaints between the 2002 and 2017 surveys. For both boys and girls, the rate of endorsing the subjective perception of "being healthy" was higher in 2017 than in 2002. In contrast, the rate of "doing exercise outside of regular physical education classes" by girls was significantly higher in 2002 than in 2017 ( $p=.028)$. Additionally, the rate of watching television for more than 3 hours was higher in 2002 than in 2017 for both boys and girls $(p<.0001)$. Although the total sleep time did not significantly differ between the 2002 and 2017 surveys for boys, it was shorter in 2017 than in 2002 for girls $(p=.005)$. Furthermore, both boys and girls generally had more complaints in 2002 than in 2017. The items that showed a statistically significant difference between 2002 and 2017 for both boys and girls were as follows: "feeling stressed," "want a day off to rest," "often have a headache," and "feeling dizzy." There were significant differences in 10 of the 18 items in boys. Overall, there were significant differences in 12 items. Students in 2017 were less physically active, watched television for lesser time, and slept for less hours than those in 2002 but had fewer physical problems and considered themselves healthier.

\subsection{Family Smoking Habits and Students' Perceptions Regarding Smoking}

Table 5 shows the results of comparisons in the presence of smokers in the family and students' perceptions of this issue between the 2002 and 2017 surveys. The proportion of students with smokers in the family was lower in 2017 than in 2002 for both boys and girls $(p<.0001)$. More specifically, the proportion of students with fathers who smoked was significantly lower in 2017 than in 2002 for both boys and girls $(p<.0001)$; there were no other significant differences between 2002 and 2017 in terms of other family members who smoked. Regarding smoking areas, the rate of smoking in indoor living areas was lower in 2017 than in $2002(p<.0001)$, while the rate of smoking outside the house was higher in 2017 than in 2002. Both boys and girls indicated that they wanted their family members to stop smoking at a higher rate in 2017 than in 2002. Additionally, the rate of "intending to smoke in the future" was lower in 2017 than in 2002 for both boys and girls, with no girls responding "yes" to this item. Compared to the data obtained 15 years ago, the data of 2017 showed a sharp decrease in the number of smokers in the family. The students also showed aversion toward tobacco. 
Table 4. Comparisons of lifestyle and daily complaints between the 2002 and 2017 surveys according to sex

\begin{tabular}{|c|c|c|c|c|c|c|c|c|c|c|c|c|c|c|c|c|}
\hline & & Male & & & & & Female & & & & & Total & & & & \\
\hline & & 2002 & & 2017 & & & 2002 & & 2017 & & & 2002 & & 2017 & & \\
\hline & & $n=293$ & & $\mathrm{n}=137$ & & & $\mathrm{n}=287$ & & $\mathrm{n}=166$ & & & $\mathrm{n}=580$ & & $\mathrm{n}=303$ & & \\
\hline & & $\begin{array}{l}\mathrm{N} \text { or } \\
\text { Mean }\end{array}$ & $\begin{array}{l}\% \text { or } \\
\mathrm{SD}\end{array}$ & $\begin{array}{l}\mathrm{N} \text { or } \\
\text { Mean }\end{array}$ & $\begin{array}{l}\% \text { or } \\
\mathrm{SD}\end{array}$ & $p$ & $\begin{array}{l}\mathrm{N} \text { or } \\
\text { Mean }\end{array}$ & $\begin{array}{l}\% \text { or } \\
\mathrm{SD}\end{array}$ & $\begin{array}{l}\mathrm{N} \text { or } \\
\text { Mean }\end{array}$ & $\begin{array}{l}\% \text { or } \\
\mathrm{SD}\end{array}$ & $p$ & $\begin{array}{l}\mathrm{N} \quad \text { or } \\
\text { Mean }\end{array}$ & $\begin{array}{l}\% \text { or } \\
\mathrm{SD}\end{array}$ & $\begin{array}{l}\mathrm{N} \text { or } \\
\text { Mean }\end{array}$ & $\begin{array}{l}\% \text { or } \\
\mathrm{SD}\end{array}$ & $p$ \\
\hline \multicolumn{17}{|c|}{ Lifestyle } \\
\hline 1 & Think they are healthy/YES & 201 & 68.6 & 85 & 62.0 & $.003 *$ & 179 & 62.4 & 119 & 71.7 & $.020^{*}$ & 380 & 65.5 & 204 & 67.3 & $.012 *$ \\
\hline 2 & Taking regular exercise/YES & 204 & 69.6 & 100 & 73.0 & .644 & 171 & 59.6 & 96 & 57.8 & .762 & 375 & 64.7 & 196 & 64.7 & .787 \\
\hline 3 & $\begin{array}{l}\text { Doing exercise other than physical } \\
\text { education/YES }\end{array}$ & 238 & 81.2 & 114 & 83.2 & .783 & 201 & 70.0 & 97 & 58.4 & $.028 *$ & 439 & 75.7 & 211 & 69.6 & .072 \\
\hline 4 & Taking extra private lessons/YES & 201 & 68.6 & 89 & 65.0 & .373 & 207 & 72.1 & 108 & 65.1 & .230 & 408 & 70.3 & 197 & 65.0 & .141 \\
\hline 5 & $\begin{array}{l}\text { Watching television for } 3 \text { hours or } \\
\text { more per day/YES }\end{array}$ & 140 & 47.8 & 38 & 27.7 & $\begin{array}{l}<.001 \\
* *\end{array}$ & 148 & 51.6 & 52 & 31.3 & $\begin{array}{l}<.001 \\
* *\end{array}$ & 288 & 49.7 & 90 & 29.7 & $\begin{array}{l}<.00 \\
1 * *\end{array}$ \\
\hline & Total sleep time ${ }^{\dagger}$ & 8.0 & 1.11 & 7.9 & 0.84 & .134 & 7.8 & 1.07 & 7.5 & 1.16 & $.005 *$ & 7.9 & 1.12 & 7.7 & 1.00 & $0.02 *$ \\
\hline \multicolumn{17}{|c|}{ Various symptoms (yes/no) } \\
\hline 1 & Feeling stressed/YES & 55 & 18.8 & 9 & 6.6 & $.001 *$ & 71 & 24.7 & 18 & 10.8 & $\begin{array}{l}<.001 \\
* *\end{array}$ & 126 & 21.7 & 27 & 8.9 & $\begin{array}{l}<.00 \\
1 * *\end{array}$ \\
\hline 2 & Feeling tired often/YES & 63 & 21.5 & 24 & 17.5 & .369 & 84 & 29.3 & 26 & 15.7 & $.001 *$ & 147 & 25.3 & 50 & 16.5 & $.003^{*}$ \\
\hline 3 & Feeling sleepy/YES & 176 & 60.1 & 63 & 46.0 & $.007 *$ & 192 & 66.9 & 100 & 60.2 & .156 & 368 & 63.4 & 163 & 53.8 & $.006^{*}$ \\
\hline 4 & Having tired eyes/YES & 68 & 23.2 & 21 & 15.3 & .073 & 98 & 34.1 & 39 & 23.5 & $.019 *$ & 166 & 28.6 & 60 & 19.8 & $.004 *$ \\
\hline 5 & Want a day off to rest/YES & 101 & 34.5 & 29 & 21.2 & $.005^{*}$ & 124 & 43.2 & 40 & 24.1 & $\begin{array}{l}<.001 \\
* *\end{array}$ & 225 & 38.8 & 69 & 22.8 & $\begin{array}{l}<.00 \\
1 * *\end{array}$ \\
\hline 6 & Difficulty sleeping at night/YES & 27 & 9.2 & 9 & 6.6 & .456 & 26 & 9.1 & 17 & 10.2 & .740 & 53 & 9.1 & 26 & 8.6 & .901 \\
\hline 7 & Trouble thinking/YES & 50 & 17.1 & 10 & 7.3 & $.007 *$ & 52 & 18.1 & 27 & 16.3 & .700 & 102 & 17.6 & 37 & 12.2 & $.041^{*}$ \\
\hline 8 & Getting annoyed easily/YES & 75 & 25.6 & 28 & 20.4 & .276 & 81 & 28.2 & 44 & 26.5 & .744 & 156 & 26.9 & 72 & 23.8 & .332 \\
\hline 9 & Lose patience often/YES & 46 & 15.7 & 10 & 7.3 & $.020^{*}$ & 34 & 11.8 & 11 & 6.6 & .102 & 80 & 13.8 & 21 & 6.9 & $.002 *$ \\
\hline 10 & Do not want to talk/YES & 29 & 9.9 & 5 & 3.6 & $.033 *$ & 33 & 11.5 & 12 & 7.2 & .192 & 62 & 10.7 & 17 & 5.6 & $.013 *$ \\
\hline 11 & Want to shout and run wild/YES & 53 & 18.1 & 14 & 10.2 & $.045^{*}$ & 56 & 19.5 & 21 & 12.7 & .069 & 109 & 18.8 & 35 & 11.6 & $.005^{*}$ \\
\hline 12 & No motivation/YES & 79 & 27.0 & 16 & 11.7 & $\begin{array}{l}<.001 \\
* *\end{array}$ & 81 & 28.2 & 36 & 21.7 & .148 & 160 & 27.6 & 52 & 17.2 & $.001 *$ \\
\hline 13 & Frequent headache/YES & 45 & 15.4 & 9 & 6.6 & $.012 *$ & 64 & 22.3 & 23 & 13.9 & $.035^{*}$ & 109 & 18.8 & 32 & 10.6 & $.001 *$ \\
\hline
\end{tabular}




\begin{tabular}{|c|c|c|c|c|c|c|c|c|c|c|c|c|c|c|c|c|}
\hline 14 & Stiff shoulders and joints/YES & 38 & 13.0 & 14 & 10.2 & .526 & 53 & 18.5 & 25 & 15.1 & .370 & 91 & 15.7 & 39 & 12.9 & .273 \\
\hline 15 & Legs and arms hurt often/YES & 48 & 16.4 & 14 & 10.2 & .105 & 45 & 15.7 & 23 & 13.9 & .683 & 93 & 16.0 & 37 & 12.2 & .135 \\
\hline 16 & Feeling dizzy/YES & 79 & 27.0 & 14 & 10.2 & $\begin{array}{l}<.001 \\
* *\end{array}$ & 98 & 34.1 & 32 & 19.3 & $.001 *$ & 177 & 30.5 & 46 & 15.2 & $\begin{array}{l}<.00 \\
1 * *\end{array}$ \\
\hline 17 & Stomach pain/YES & 36 & 12.3 & 14 & 10.2 & .629 & 36 & 12.5 & 17 & 10.2 & .545 & 72 & 12.4 & 31 & 10.2 & .378 \\
\hline 18 & Constipation or diarrhea/YES & 9 & 3.1 & 5 & 3.6 & .774 & 15 & 5.2 & 15 & 9.0 & .121 & 24 & 4.1 & 20 & 6.6 & .142 \\
\hline
\end{tabular}

$* p<.05, * * p<.001$ calculated using Fisher's exact test, unless otherwise indicated; $\uparrow:$ unpaired $\mathrm{t}$-test; $\mathrm{p}$-values are two-tailed.

Sleep time is expressed in hours. Non-responses were excluded. SD: standard deviation

Table 5. Comparisons of smoking habits of students' families between the 2002 and 2017 surveys

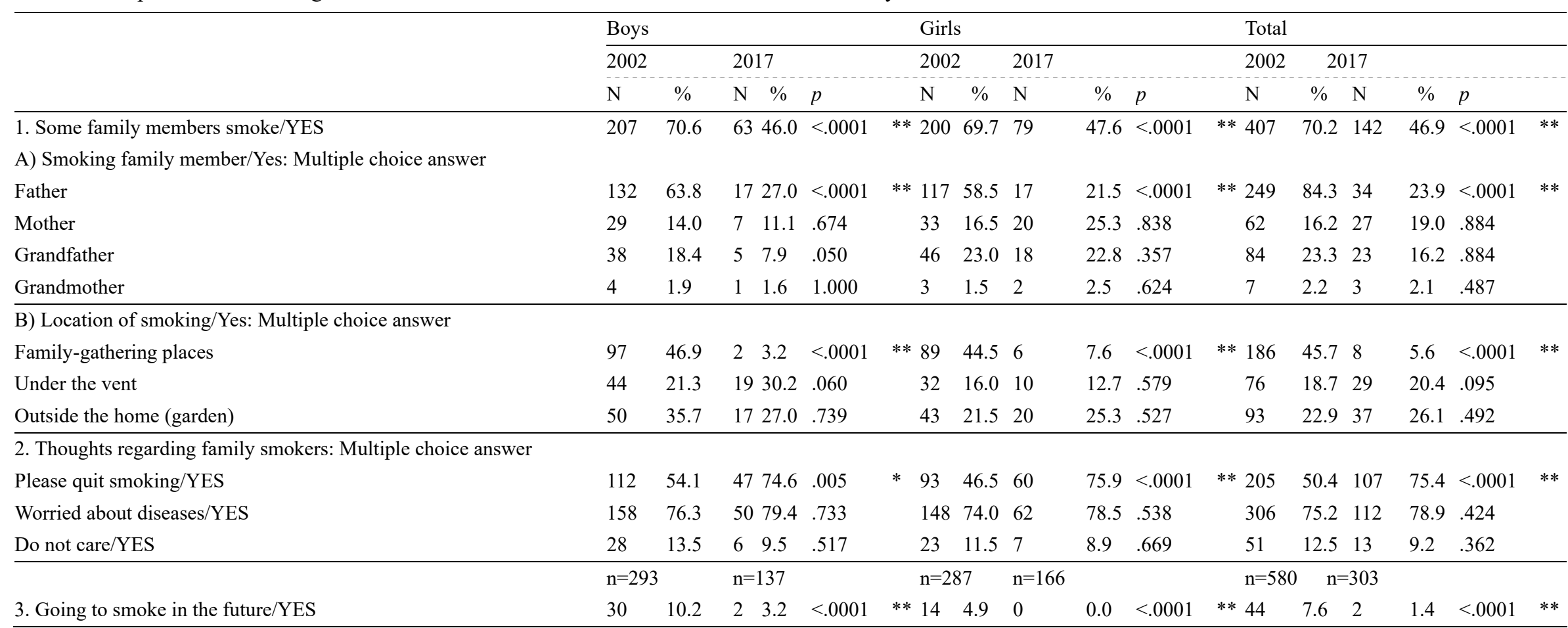

$* p<.05, * * p<.001$ by Fisher's exact test, unless otherwise indicated; $\uparrow:$ unpaired t-test; $\mathrm{p}$-values are two-tailed. Sleep time is in hours. Non-responses were excluded. 


\section{Discussion}

This study was conducted to describe the lifestyle and mental and physical status of students in Town A, rural Japan, and compare the results to those of a similar study conducted in 2002.

Regarding changes in physique over a period of 15 years (from 2002 to 2017), height and weight increased slightly for both boys and girls of all ages, with a statistically significant difference found in the height and weight of girls in the second year of junior high school. A school health survey conducted by MEXT reported that student height has flattened from a peak occurring from 1994 to 2001, and student weight, which peaked from 1998 to 2006, has fallen or stayed level. The present study results differ in that the physique of girls improved rather than leveling off. This suggests that, in terms of height and weight, the girls of Town A do not follow the national trends in Japan.

Many high-income countries have reported a recent decrease in students' physical activity levels (Matta et al., 2021). The trend in Japan appears to be similar, with reports suggesting that students' physical constitution and amount of exercise have declined compared to that 30 years ago (Tanaka et al., 2016). In Japan, the Child Safety Project has been promoted by MEXT since 2002, expanding the use of school buses across the country, as a policy to prevent accidents on the way to and from school and to ensure traffic safety. At the same time, the Ministry began to recommend a reduction in club activities in the early morning and evening. It can be assumed that these social phenomena have contributed to the decline in students' physical activities. The large decrease in complaints over the past 15 years suggests that the physical demands of school life have been reduced.

Numerous studies have examined the relationship between obesity and media as a relevant factor in student inactivity. Some reports have linked obesity in children to media use (Schneider et al., 2007), and screen time to a sedentary home environment (Conlon et al., 2019). In the present study, obesity did not significantly differ between the 2002 and 2017 surveys in any age group; however, the proportion of students who spent more than three hours in watching television was lower in 2017 than in 2002. In contrast, there was a significant decrease in sleep duration. This indicates that over the 15 -year period, sleep duration decreased due to activities that replaced watching television. In 2002, there was limited use of games and social media on mobile phones or smartphones among Japanese children and students. Smartphones were released in the United States in 2007 and in Japan in 2008. A number of studies have argued that this has resulted in changes in activities and the sleep time of children and students (Kato et al., 2018) (Wada et al., 2019). Thus, the current survey is significant in that it was able to clarify the changes in lifestyle habits of the same type of students in the same location in Japan before and after the release of smartphones (mobile phones).

Compared to that in 2002 (before mobile phones appeared), the apparent reductions in sleep duration, television viewing, and exercise outside of physical education classes among children were significant, indicating a change in lifestyle. Interestingly, the increase in the proportion of students who feel that they are "healthy" was statistically significant. The development of digital communication is said to have both positive and negative effects on adolescent health (Favotto et al., 2017), although many studies have drawn negative conclusions in this regard (Hoge et al., 2017). However, there is a direct relationship between adolescent media literacy and psychological well-being (Bahramian et al., 2018), and the lifestyle changes associated with 15 years of digital advancements may have increased students' self-esteem.

According to a survey conducted by Japan's Ministry of Health in 2005, 12.2\% of boys and 3.4\% of girls in high schools smoked every day (Osaki et al., 2012). The significant reduction in students' exposure to passive smoking and their increased negative feelings toward smoking were the most important findings of the current study. These results indicate that the smoking environment has improved, suggesting future positive changes, as the surrounding smoking environment is known to directly impact the rate of future smoking in students. Moreover, the current study results show that even in rural areas with high rates of elderly people and smoking, there is a shift toward healthier lifestyles in children. This may be due to several reasons, including the introduction of "Taspo" cards for accessing tobacco vending machines in 2008. Taspo cards are encoded with the user's details and are designed to prevent underage tobacco usage (Katanoda et al., 2014). Additionally, in 2000 and 2001, penalties for the sale of tobacco products to minors were strengthened by amendments to the Minor Smoking Prohibition Law and Minor Drinking Prohibition Law, which could be another reason for the significant reduction in exposure to smoking (Ministry of Health, Labour and Welfare, 2015). The final result of all these preventive measures showed a highly significant reduction in students' exposure to passive smoking, which will prevent many health hazards in the future. However, Japan has no national legislation prohibiting indoor smoking as part of the process of preventing passive smoking. In addition, the use of e-cigarettes has increased in recent years, with young people perceiving these cigarettes as less harmful than regular cigarettes (Jiang et al., 2019). Future health studies will need to continue to examine changes in smoking rates and perceptions due to the introduction of e-cigarettes. 


\subsection{Limitations}

This study compared data from surveys conducted in Town A in 2002 and 2017. Due to a rapid decline in the youth population in this rural area, there were only 303 student responders in 2017, almost half of that in 2002 (580). However, the effect of this factor was reduced by applying the same methodology used in 2002.

This survey data may appear outdated, but this is the latest data available for this town. This is because a full student-survey is only conducted every 10 to 15 years here.

\section{Conclusion}

The study results suggest that the lifestyle of children in rural Japan has improved over the past 15 years. Additionally, children have a more negative attitude about smoking in the future. However, more attention to technology-related lifestyle issues, including television watching and Internet usage is needed.

\section{Acknowledgments}

We would like to acknowledge and thank Dr. Mio Tanaka $(\mathrm{PhD})$ for her advice. We also thank the elementary and junior high school principals in Tagami-machi for their valuable advice.

We would like to thank Editage [http://www.editage.com] for assistance in editing and reviewing this manuscript for English language.

\section{Funding}

None.

\section{Competing Interests Statement}

All authors have no potential conflicts of interest.

\section{References}

Arakawa, M., Taira, K., Tanaka, H., Yamakawa, K., Toguchi, H., Kadekaru, H., ... \& Shirakawa, S. (2001). A survey of junior high school students' sleep habit and lifestyle in Okinawa. Psychiatry Clin Neurosci, 55, 211-212. https://doi.org/10.1046/j.1440-1819.2001.00829.x

Bahramian, E., Mazaheri, M. A., \& Hasanzadeh, A. (2018). The relationship between media literacy and psychological well-being in adolescent girls in Semirom city. J Educ Health Promot, 7, 148.

Conlon, B.A., Mcginn, A.P., Isasi, C.R., Mossavar-Rahmani, Y., Lounsbury, D.W., Ginsberg, MS., ... \& Wylie-Rosett, J. (2019). Home environment factors and health behaviors of low-income, overweight, and obese youth. Am J Health Behav, 43, 420-436. https://doi.org/10.5993/ajhb.43.2.17

Favotto, L., Michaelson, V., \& Davison, C. (2017). Perceptions of the influence of computer-mediated communication on the health and well-being of early adolescents. Int J Qual Stud Health Well-being, 12, 1335575. https://doi.org/10.1080/17482631.2017.1335575

Fukuda, Y., Nakamura, K., \& Takano, T. (2005). Socioeconomic pattern of smoking in Japan: income inequality

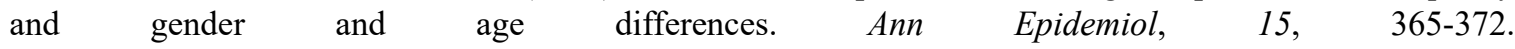
https://doi.org/10.1016/j.annepidem.2004.09.003

Hoge, E., Bickham, D., \& Cantor, J. (2017). Digital media, anxiety, and depression in children. Pediatrics, 140, S76-S80. https://doi.org/10.1542/peds.2016-1758g

Japan Sport Council. (2001). Initiatives at all schools (accident prevention measures) (in Japanese). Retrieved May 15, 2019, from https://www.jpnsport.go.jp/anzen/tabid/1923/Default.aspx

Jiang, N., Cleland, C. M., Wang, M. P., Kwong, A., Lai, V., \& Lam, T. H. (2019). Perceptions and use of e-cigarettes among young adults in Hong Kong. BMC Public Health, 19, 1123. https://doi.org/10.1186/s12889-019-7464-Z

Katanoda, K., Jiang, Y., Park, S., Lim, M. K., Qiao, Y. L., \& Inoue, M. (2014). Tobacco control challenges in East Asia: proposals for change in the world's largest epidemic region. Tob Control, 23, 359-368. https://doi.org/10.1136/tobaccocontrol-2012-050852

Kato, T., Yorifuji, T., Yamakawa, M., \& Inoue, S. (2018). National data showed that delayed sleep in six-year-old children was associated with excessive use of electronic devices at 12 years. Acta Paediatr, 107, 1439-1448. https://doi.org/10.1111/apa.14255

Kotani, K., Nishida, M., Yamashita, S., Funahashi, T., Fujioka, S., Tokunaga, K., ... \& Matsuzawa, Y. (1997). Two 
decades of annual medical examinations in Japanese obese children: do obese children grow into obese adults? Int J Obes Relat Metab Disord, 21, 912-921. https://doi.org/10.1038/sj.ijo.0800492

Manning, K., Senekal, M., \& Harbron, J. (2016). Non-communicable disease risk factors and treatment preference of obese patients in Cape Town. Afr $J$ Prim Health Care Fam Med, 8, e1-12. https://doi.org/10.4102/phcfm.v8i1.913

Matta, P. N., Baul, T. D., Loubeau, K., Sikov, J., Plasencia, N., Sun, Y., \& Spencer, A. E. (2021). Low sports participation is associated with withdrawn and depressed symptoms in urban, school-age children. $J$ Affect Disord, 280, 24-29. https://doi.org/10.1016/j.jad.2020.11.076

Ministry of Education, Culture, Sports, Science and Technology in Japan. (2018). [Health survey by Education Policy Bureau (in Japanese). Retrieved March 19, 2019, from http://www.mext.go.jp/component/b_menu/other/_icsFiles/afieldfile/2018/03/26/1399281_03_1.pdf

Ministry of Health, Labour and Welfare. (2015). [E-health net] (in Japanese). Retrieved July 10, 2020, from https://www.e-healthnet.mhlw.go.jp/information/dictionary/alcohol/ya-065.html

Ministry of Health, Labour and Welfare. (2016). [Healthy Life Extension Plan] (in Japanese). Retrieved March 10, 2019, from https://www.mhlw.go.jp/content/12601000/000514142.pdf

Ministry of Internal Affairs and Communications. (2017). White paper on Information and Communications Technology in 2017. Retrieved March 10, 2019, from https://www.soumu.go.jp/johotsusintokei/whitepaper/ja/h29/html/nc262510.html

Osaki, Y., Ohida, T., Kanda, H., Kaneita, Y., \& Kishimoto, T. (2012). Mobile phone use does not discourage adolescent smoking in Japan. Asian Pac $J$ Cancer Prev, 13, 1011-1014. https://doi.org/10.7314/apjcp.2012.13.3.1011

Schneider, M., Dunton, G. F., \& Cooper, D. M. (2007). Media use and obesity in adolescent females. Obesity (Silver Spring), 15, 2328-2335. https://doi.org/10.1038/oby.2007.276

Tagami Town Health Management Center. (2003). Tagami Town's official health survey report: Results of a survey of children's lifestyle habits. (in Japanese). Retrieved July 10, 2018, from http://www.town.tagami.niigata.jp/living/ho/images/keikaku3-1.pdf

Tagami town, Niigata statistics. (2020). [Town administration information] (in Japanese). Retrieved December 10, 2020, from http://www.town.tagami.niigata.jp/adm/adm16.html

Tanaka, C., Reilly, J.J., Tanaka, M., \& Tanaka, S. (2016). Seasonal changes in objectively measured sedentary behavior and physical activity in Japanese primary school children. BMC Public Health, 16, 969. https://doi.org/10.1186/s12889-016-3633-5

Urakami, T., Suzuki, J., Mugishima, H., Amemiya, S., Sugihara, S., Kawamura, T., ... \& Kitagawa, T. (2012). Screening and treatment of childhood type 1 and type 2 diabetes mellitus in Japan. Pediatr Endocrinol Rev, 10, 51-61.

Wada, K., Yamakawa, M., Konishi, K., Goto, Y., Mizuta, F., Koda, S., ... \& Nagata, C. (2019). Associations of cell phone use and screen viewing with overweight in children. Child Obes, 15, 417-425. https://doi.org/10.1089/chi.2018.0312

World Health Organization. (2016). WHO: Non-Communicable Diseases Fact Sheet. Retrieved March 10, 2019, from http://www.who.int/mediacentre/factsheets/fs355/en/ 


\section{Appendix}

Please circle the number that you think is applicable.

Please tell me about yourself.

Age male / female

$<$ About other daily life $>$

1) Do you exercise often?
1. Yes
2. No

2) What time do you get up and what time do you go to bed?

Please write the time

I will go to bed around

I get up around

3) TV (including movies, video games, computers) How long do you watch or play them?

1. Not at all

2. Less than 1 hour

3. 1 hours to 2 hours

4. 2 hours to 3 hours

5. 3 hours to 4 hours

6. 4 hours or more

4) Do you think you need exercise?
1. Yes
2. No

5) Do you think that you are healthy?

1. Yes

2. No

6) Do you exercise other than PE class?

1. Yes No

7) Do you go to private school such as Juku or take some lessons (including sports classes)?

1. Yes (How often do you take them a week?)

2. No

8) Do you think you are lacking sleep?
1. Yes
2. No 
$<$ About the Internet $>$

1) What is the one that you have exclusively for yourself? (please mark all that apply)

1. cell phone (including smart phones)

2. computers

3. iPad

4. 3DS

5. PSP

6. others that connected Internet

7. do not have

2) On week days, how long do you use Internet a day?
1. Not at all
2. Less than one hour
3. 1-2 hours
4. 2-3 hours
5. 3-4 hours
6. 4 hours

3) Can Internet video watching and playing games be uninterrupted and other things neglected?
1. Yes
2. No

4) Is there anything you think is more fun to watch internet videos and play games than spend time with family?
1. Yes
2. No

5) Do you think that life will be enriched if there is social media connected via the Internet?
1. Yes
2. No

$<$ About Smoking $>$

1) Is there any family member that smokes in your family?
1. Yes
2. No

*please answer that marked "yes"

(1)Who are they? Please mark that applies all.

1. Father 2. Mother 3. Brother 4. Sister 5. Grand Father.

6. Grandmother 7. Others

(2)Where do they smoke?

1. family gathering space (living room, dining room)

2. under the vent at kitchen 3. Outside (including veranda)

4. Other places (

(3)What do you think of them smoking? Please mark that applies all.
1. Please quit
2. Worried about disease
3. Do not care

4. others ( 
2) Do you think you are going to smoke?
1. will smoke
2. May smoke
3. May not smoke
4 definitely not smoke

3) Those who marked 1, or 2, please answer why you think so.

4) Those who marked 3, or 4, please answer why you think so.

(

$<$ State of mind and body $>$

1) What kind of symptoms or feelings do you feel in daily life? Please mark all that applies.

1. Heavy head, vague

2. Feel tired and listlessness

3. Sleepy

4. My eyes are tired.

5. Want to take a day off with my body lying down.

6. Can not sleep at night.

7. Trouble thinking clearly

8. Get annoyed

9. To lose patience

10. Do not want to talk with people

11. Want to make a loud voice and go all out rampage

12. Nothing motivated

13. My head is in pain.

14. My shoulders are stiff (heavy)

15. My waist, legs and arms hurt.

16. Tummy hurts

17. When standing up suddenly, I feel to be faint, dizziness (head hurts).

18. To have constipation or diarrhea

2) What do you think is the reason for feeling something like you circled above?

1. Sleep shortage $\quad 2$. Tired from club activities and exercise

3. Long time for TV and games 4. Studying is difficult

5. There is worry $\quad 6$. Irregular meal

7. Other ( )

$<$ Lastly $>$

When you go home, who are they always be at home

Mark all that applies
1. Father
2. Mother
3. Grandparents
4. Siblings
5. None
6. others (
)

Questions are all. Thank you for your cooperation. 


\section{Copyrights}

Copyright for this article is retained by the author(s), with first publication rights granted to the journal.

This is an open-access article distributed under the terms and conditions of the Creative Commons Attribution license (http://creativecommons.org/licenses/by/4.0/). 